\title{
IMPORTÂNCIA DA ATIVIDADE ARTESANAL DE MARISCAGEM PARA AS POPULAÇÕES NOS MUNICÍPIOS DE MADRE DE DEUS E SAUBARA, BAHIA
}

\author{
Rosenaide Santos Jesus* \\ Catherine Prost**
}

\section{RESUMO}

O presente estudo teve como objetivo analisar os aspectos socioambientais relacionados à atividade de mariscagem desenvolvida nos municípios de Madre de Deus e Saubara, Bahia. Para atingir o objetivo proposto foi realizado levantamento de dados; foram aplicados questionários contendo questões relativas a dados socioeconômicos dos entrevistados, espécies animais mais coletadas, principais modificações ocorridas no ecossistema manguezal; e foi feita observação direta da área de estudo. Os dados foram tabulados em planilhas eletrônicas e interpretados. Verificou-se que a atividade de mariscagem é desenvolvida nos dois municípios por populações de baixo ou nenhum poder aquisitivo. Estas atividades estão comprometidas devido ao estado de conservação do ecossistema manguezal e consequentemente dos produtos deste.

Palavras chave: atividade artesanal, mariscagem, Madre de Deus, Saubara, análise socioambiental.

\section{ABSTRACT}

The present study has the objective of analyzing the socio-environmental aspect of the shellfish activity, developed in the counties of Madre de Deus and Saubara, Bahia. To achieve the proposed objective data collection was performed questionnaires with questions related to the socio-economic data of the respondents, more abundant species and the principal changes occurred in the mangrove ecosystem; and was deed direct observation of the study. The data were tabulated on spreadsheets and interpreted. It was observed that the shellfish activity is developed in the two counties per populations with low or without purchasing power. These activities are compromised because of the state of conservation of mangrove ecosystem and, therefore, the resources of this habitat.

Keywords: handmade activity, shellfish, Madre de Deus, Saubara, socio-environmental analysis.

\section{INTRODUÇÃO}

O manguezal é um ecossistema costeiro que se desenvolve na faixa intertropical em condições específicas, resultado da interação das águas do rio com as águas do mar. A sua estrutura varia em função da biogeografia e das condições ambientais locais (VANNUCCI, 2002), contribuindo, dessa forma, para a existência dos diversos tipos de estrutura de manguezal por todo o mundo. É um ecossistema muito importante (SOUTO, 2008), pois fornece proteção às costas e é um verdadeiro habitat para a colonização de animais (VANNUCCI, 2002).

No Brasil, os manguezais têm sido utilizados para a exploração de madeira e como fonte de subsistência. Sua importância ecológica foi 
fortemente reconhecida a partir do período colonial com a promulgação de leis acerca da extração de madeira para a produção de tanino (VANNUCCI, 2002). Atualmente alguns dos usos tradicionais vêm convivendo com novas utilizações decorrentes do crescimento industrial, urbano e portuário que vem acontecendo em amplas áreas de manguezal (CARDOSO, 2003). Atualmente, em toda a costa brasileira regiões de manguezal são verdadeiras fontes de recursos para populações carentes que retiram dali o seu sustento, como é o caso das áreas de estudo de Madre de Deus e Saubara, na Baía de Todos os Santos. A atividade de mariscagem, portanto, é considerada "uma forma não predatória de uso dos recursos" (CARDOSO, 2003, p. 7).

A mariscagem em Madre de Deus e Saubara é uma atividade realizada de forma artesanal, tanto para consumo próprio quanto para venda. A origem dessa atividade remonta ao período de ocupação dos primeiros habitantes da BTS como comprova a presença de sambaquis na beira de suas águas. Porém esta atividade está cada vez mais comprometida devido aos impactos provenientes das atividades petrolíferas e ao consequente aumento da população na Baía de Todos os Santos (BTS), como se observa nos dois municípios estudados, com mais intensidade em Madre de Deus. Ali, a instalação da Petrobrás atraiu migrantes em busca de emprego, gerando significativas transformações físico-ambientais (BRADLEY et al., 2000; PIMENTEL, 2006). Uma das consequências foi a significativa redução em termos de coleta de mariscos, assim como de captura de peixes.

No município de Saubara, observase situação semelhante com redução na coleta e mortandade entre certas espécies, entre outras situações. Este quadro é devido, em parte, ao despejo de esgoto doméstico e de lixos nos manguezais, principalmente à presença de contaminantes oriundos de atividades industriais e ao aumento da população. A degradação é menos intensa que no município de Madre de Deus.

A realidade da atividade de mariscagem, assim como o estado em que se encontra o ecossistema manguezal nos dois municípios foram os fatores motivadores para o desenvolvimento do presente estudo que teve como objetivo analisar os aspectos socioambientais relacionados à atividade de mariscagem desenvolvida nos municípios de Madre de Deus e Saubara, BA.

\section{ÁREA DE ESTUDO}

As áreas de estudo localizam-se no centro-norte e oeste da Baía de Todos os Santos, nos municípios de Madre de Deus - entre as coordenadas $38^{\circ} 36^{\prime} 32^{\prime \prime}$ a $38^{\circ} 35^{\prime} 35^{\prime \prime} \mathrm{W}$ e $12^{\circ} 43^{\prime} 36^{\prime \prime}$ a $12^{\circ} 44^{\prime} 37^{\prime \prime S}$ - abrangendo as localidade Suape e Cação; e Saubara - área localizada entre as coordenadas $38^{\circ} 45^{\prime} 32^{\prime \prime}$ a $38^{\circ} 44^{\prime} 14^{\prime \prime} \mathrm{W}$ e $12^{\circ} 43^{\prime} 59^{\prime \prime}$ a $12^{\circ} 47^{\prime} 06^{\prime \prime} \mathrm{S}$-, nas localidades denominadas Iraque e Porto (Figura 1).

A ocupação das áreas de estudo é um reflexo do modo de ocupação da Baía de Todos os Santos. A BTS está localizada a leste do estado da Bahia e tem aproximadamente $1.200 \mathrm{~km}^{2}$. Sua configuração atual é resultado de um rift formado durante a separação entre a América do Sul e África e de posterior preenchimento com materiais da Bacia Sedimentar do Recôncavo (DOMINGUEZ e BITTENCOURT, 2009). O seu entorno é composto por 14 municípios (COUTO et al., 1997): Cachoeira, Candeias, Itaparica, Jaguaripe, Madre de Deus, Maragogipe, Salinas das Margaridas, Salvador, Santo Amaro, São Francisco do Conde, São Félix, Saubara, Simões Filho e Vera Cruz. Possui uma área composta pelas microrregiões econômicas de Salvador, Região Metropolitana de Salvador, Recôncavo e Recôncavo Sul (BAHIA, 1994).

Há ainda na BTS um aglomerado de ilhas, entre elas a ilha dos Frades, Maria Guarda, Bom Jesus, Paty, Fontes, Vacas, Bimbarra e a Ilha de Madre de Deus. Já na parte oeste da BTS podem ser encontradas inúmeras localidades que se desenvolveram próximas a ambientes densos de manguezais, como São Brás, Acupe e Saubara. Todas estas áreas já sentem as consequências da poluição na BTS, o que compromete a pesca e a mariscagem na região. Uma área menos impactada pela poluição industrial é Baía do Iguape, no baixo rio Paraguaçu, a jusante da cidade de Cachoeira. É uma região marcada por manguezais produtivos e 
cidades onde podem ser encontrados vestígios de engenhos (BRITO, 1997).
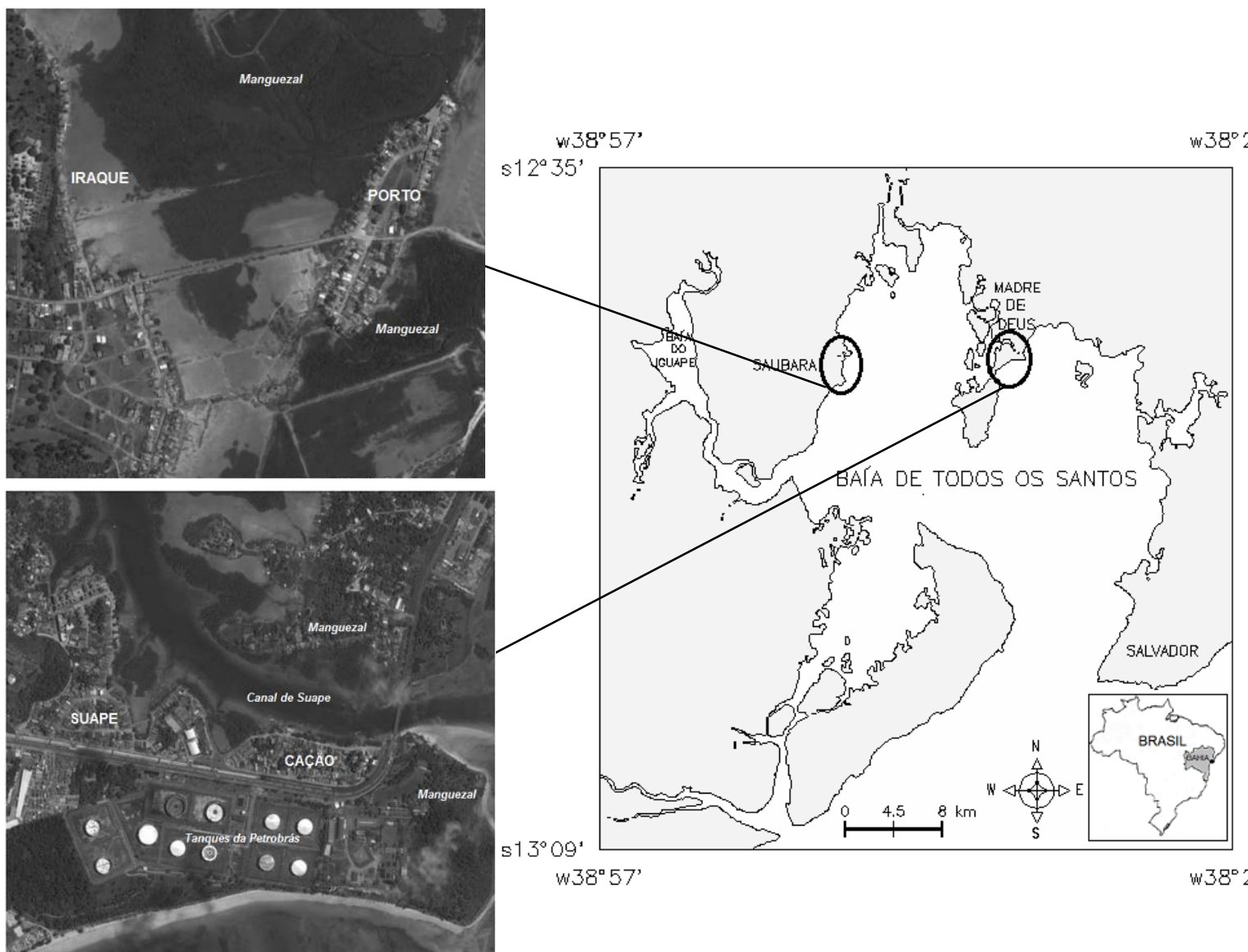

w3 $38^{\circ} 57^{\prime}$

Figura 1: Imagem de localização da área de estudo (GOOGLE, 2010; 2009), na Baía de Todos os Santos, adaptado (HADLICH e UCHA, 2008).

A BTS foi ocupada inicialmente pelos índios Tupinambás, que tinham uma economia de subsistência. Posteriormente os portugueses entraram em confronto com os Tupinambás. Com a colonização foi iniciado o cultivo da cana-de-açúcar, principal atividade econômica, complementada pela pecuária, com consequente devastação da Mata Atlântica e introdução de novas espécies de plantas e animais. Nesse mesmo período aconteceram a destribalização dos índios e profundas mudanças culturais com a chegada dos africanos e portugueses (FONSECA, 1997).

O cultivo da cana-de-açúcar, por volta do século XIX, entrou em declínio e posteriormente entrou em decadência com a descoberta e exploração do petróleo. Assim, no século XX, por volta dos anos 50 , houve mudanças significativas, reflexo do modelo de expansão capitalista no Recôncavo. Cita-se a introdução de novos hábitos e costumes devido à chegada de migrantes. Outra transformação foi a diminuição significativa no número de pescadores e mariscadores, por serem estes atraídos pelas possíveis ofertas de empregos e devido à diminuição da fauna nos rios próximos e na baía por causa de casos de derrame de óleo de navios e lançamento de detritos industriais no 
oceano (OLIVEIRA, 1997).

A primeira refinaria da Petrobrás começou a funcionar em 18 de setembro de 1950 em Mataripe, próximo a Candeias, o que resultou no processo de industrialização da região. Estimulados também pela oferta de infraestrutura pelo Estado e o fornecimento de energia pela Companhia Hidrelétrica do São Francisco (CHESF) surgiu o Complexo Industrial de Aratu (CIA) concentrando indústrias leves e pesadas e, mais tarde, o Pólo Petroquímico de Camaçari (OLIVEIRA, 1997).

Entre as atividades econômicas mais recentes está o turismo e tem destaque na ilha de Itaparica devido à sua localização e à implantação de hotéis, clubes, entre outros empreendimentos, estimulando a ocupação durante os finais de semana (OLIVEIRA, 1997).

\section{O município de Madre de Deus}

Madre de Deus possui uma área em torno de $32 \mathrm{~km}^{2}$. Está situada em uma zona de clima úmido a subúmido, com temperatura média anual em torno de $25,4^{\circ} \mathrm{C}$ e pluviosidade média anual entre 1.800 e $2.000 \mathrm{~mm}$, indicando baixo risco de seca (BAHIA, 1994).

A geologia do município compreende matérias do Grupo Ilhas, do Supergrupo Bahia do Cretáceo Inferior. Quanto à geomorfologia, a ilha está inserida no domínio das Bacias e Coberturas Sedimentares do Recôncavo, Unidade Baixada Litorânea. Sua cobertura vegetal é constituída por espécies da Floresta Ombrófila Densa, composta por vegetação secundária, porém bastante rarefeita, devido à intensa ocupação (BRASIL, 1981).

O município de Madre de Deus foi emancipado de Salvador em 1989, pela Lei Estadual $n^{\circ} 5016$ (BAHIA, 1994). Limita-se com os municípios de São Francisco do Conde e Salvador e margeia a BTS, integrando o grupo de municípios que compõe a região Metropolitana de Salvador. Atualmente possui uma população em torno de 17.384 habitantes (IBGE, 2010) e é composto pela Ilha de Madre de Deus e a Ilha de Maria Guarda.

A ilha de Madre de Deus, à imagem do conjunto da BTS, foi habitada por índios tupinambás, quando era então chamada Ilha de Cururupeba em homenagem ao chefe dos índios tupinambás. A ilha foi adentrada pelos portugueses após a chegada do governador Mem de Sá, em 1557 , após conflitos com os tupinambás. O vilarejo criado a partir de um engenho recebeu o nome de Madre de Deus do Boqueirão. O engenho de açúcar não prosperou devido à concorrência da Holanda, porém nesta época a ilha já possuía cerca de 50 escravos, favorecendo a miscigenação da população. Os jesuítas herdaram de Men de Sá a ilha, que foi posteriormente vendida e dividida em quatro partes às famílias de Epitáfio Queiroz, José Reis, Tomas Martins e Baltazar de Teve Argolo (ONG TERCEIRA VIA, 2005).

A ilha passou a ser ponto de apoio a embarcações, pois era considerada como localizada na metade do caminho entre as usinas de açúcar e a capital. A localidade era pequena; as principais ocupações dos habitantes eram o plantio de cana-de-açúcar, o trabalho em olarias, a pesca, a confecção de rendas, os trabalhos domésticos e o transporte marítimo de passageiros e de cargas, principalmente de açúcar. A cultura organizada da cana-de-açúcar fez com que a ilha se tornasse em um ponto estratégico na rota marítima, resultando no crescimento da Vila de Madre de Deus (ONG TERCEIRA VIA, 2005).

Após 1698 passou a fazer parte da vila de São Francisco da Barra do Sergir do Conde, até 1947. Porém, com a decadência da exploração da cana-de-açúcar, os engenhos fecharam, afetando em consequência Madre de Deus do Boqueirão. Transformou-se então numa importante região de veraneio, recebendo governadores, deputados, etc. Em 1947, passou à condição de distrito do município de Salvador (ONG TERCEIRA VIA, 2005).

A instalação da Petrobrás na década de 50 implicou inicialmente em criação de empregos e consequente aumento da renda monetária do distrito. Porém esses benefícios foram acompanhados por alterações profundas na natureza (ONG TERCEIRA VIA, 2005; PIMENTEL, 2006): o canal Boqueirão foi cavado para facilitar a entrada de navios de grande porte para embarque e desembarque de petróleo e derivado; áreas de mangue foram reduzidas e o fundo do mar implodido para a instalação de dutos em direção ao porto de Temadre, Terminal Marítimo de Madre de Deus. Houve também melhoria na infraestrutura 
com eletrificação e transporte rodoviário. Porém, com o avanço tecnológico efetivado no decorrer do tempo, reduziu-se a necessidade de mão-de-obra, levando consequentemente ao desemprego. Este foi agravado em razão do aumento da população, acompanhado de crescimento desordenado devido a uma corrente imigratória acentuada na década de 60 , fomentada pela esperança de obter emprego da indústria petrolífera. O fluxo de migrantes corroborou primeiramente a ocupação das áreas planas. Mas com o adensamento populacional, foram aterradas áreas de mangue e ocupadas encostas.

\section{O município de Saubara}

O município de Saubara possui uma área em torno de $164 \mathrm{~km}^{2}$. Está situado em área de clima úmido a subúmido, com temperatura média anual em torno de $25^{\circ} \mathrm{C}$, pluviosidade média anual entre $1600 \mathrm{~mm}$ e $1800 \mathrm{~mm}$ (BAHIA, 1994). É uma região propícia ao desenvolvimento de atividade pesqueira devido às suas condições ambientais.

Saubara localiza-se no Recôncavo baiano; limita-se a norte com Santo Amaro, a oeste com Cachoeira, a sul com Salinas da Margarida e a leste com a BTS. Faz parte da região econômica Recôncavo Sul e foi emancipado em 13 de junho de 1989 através da Lei n5 5007/89 (BARROS, 2006). Atualmente possui uma população em torno de 11.201 habitantes (IBGE, 2010).

Em relação à litologia, o município de Saubara está situado no domínio do Supergrupo Bahia, Grupo Santo Amaro (Formação Candeias), margeado pelo Grupo Brotas ambos do Cretáceo. São limitados entre si por uma falha, sendo identificada também uma pequena área ao sul do município composta por material do Holoceno Aluvionar (predominantemente arenoso), do Quaternário. Quanto à geomorfologia, o município está inserido no domínio dos Depósitos Sedimentares, na Região das Planícies Litorâneas, que engloba a unidade inferior de Planícies Marinhas e Fluviomarinhas. A vegetação da região está enquadrada como sendo de Formações Pioneiras com influência fluviomarinha (mangue), arbórea (BRASIL, 1981).

Segundo Barros (2006), Saubara, cujo nome tem origem indígena, foi inicialmente habitada por índios tupis. O povoado surgiu em um local chamado Ponta da Saubara, por volta de 1550. As terras onde hoje se localiza a Ponta da Saubara foram doadas a Fernão Rodrigues Castelo Branco que posteriormente as doou a Francisco de Sá, filho de Mém de Sá. Na região existiam duas sesmarias, onde se desenvolvia principalmente a criação de gado.

No início de 1685, no povoado fundado pelo português Braz Fragoso em terras que foram de Mém de Sá, os moradores que residiam na Ponta da Saubara resolveram construir uma igreja dedicada a São Domingos de Gusmão, que posteriormente serviu como quartel-general na luta pela Independência da Bahia, com tropas formadas por pescadores e roceiros (BARROS, 2006).

A formação político-administrativa do distrito de Saubara se deu só em de 1876. O distrito foi elevado à vila em 1955. A partir de 1983, foi organizado um movimento que lutou pela sua emancipação política, culminando com a realização de um plebiscito, em maio de 1989 e seguido da emancipação neste mesmo ano (BARROS, 2006).

O único meio de transporte no município até 1966 era o marítimo. Servia a escoar os principais produtos da economia local rural: melancia, mandioca, fumo e arroz, além de piaçava. Houve época em que Saubara exportou safras de arroz e fumo. Um dos produtos mais importante foi o azeite-de-dendê. Porém a principal atividade econômica foi, e ainda é, a pesca artesanal. O ciclo mais importante da economia de Saubara corresponde à época do apogeu dos saveiros e barcos. Os viveiros de peixe e as salinas foram, também, grandes fontes para Saubara (BARROS, 2006).

\section{MATERIAIS E MÉTODOS}

Para a realização do presente estudo foi feita primeiramente uma pesquisa bibliográfica. Em seguida o trabalho de campo consistiu na observação da área de estudo e aplicação de questionários, como descrito abaixo.

1. Pesquisa bibliográfica: levantamento, em órgãos diversos, na internet e em organizações existentes na área de estudo, do acervo disponível 
e coleta de trabalhos publicados, em meio impresso e digital, sobre a temática e as áreas em estudo. Fichamento dos materiais encontrados e publicações de interesse.

2. Trabalho de campo:

a) observação: consistiu em uma observação assistemática, não participante e individual da área de estudo e da relação das marisqueiras com o ecossistema manguezal na atividade de coleta;

b) aplicação de questionário: primeiro foi realizado um pré-teste, ou seja, a aplicação de questionários em Madre de Deus e Saubara, às marisqueiras e, houve, posteriormente, a definição da amostragem a ser realizada. Esta foi limitada aos marisqueiros e marisqueiras residentes em Madre de Deus nas localidades Cação e Suape e, em Saubara nas localidades Iraque e Porto. Após alguns ajustes na linguagem e nas opções, foi feita a aplicação efetiva dos questionários. Foram aplicados 62 questionários em Madre de Deus entre os meses de setembro e novembro de 2009 e 39 em Saubara, no mês de dezembro de 2009. O questionário contém questões relativas a dados socioeconômicos dos informantes, áreas de coleta do molusco, períodos de coleta, quantidade extraída e principais alterações observadas no decorrer do tempo, entre outras questões. Foi aplicado um questionário por família e tentou-se abranger o maior número possível de famílias de marisqueiros e marisqueiras das localidades estudadas.

3. Análise estatística dos dados: os dados foram tabulados em planilha Excel, com validação dos dados por listas para as perguntas fechadas.

\section{RESULTADOS E DISCUSSÃO}

\section{A atividade de mariscagem}

No universo da pesquisa levantada, a maior parte dos entrevistados em Madre de Deus (MD) tem entre 31 e 50 anos e em Saubara (SB) entre 19 e 50 anos.

Conforme a tabela 1 observa-se que parte significativa dos entrevistados tem longo tempo de residência nos municípios de estudo. Significa que acompanharam as principais transformações físicas nos municípios. Isto é importante para a pesquisa, espacialmente em Madre de Deus pois as transformações ocorreram de modo mais intenso ali, com aterramentos das áreas de manguezais, construções de casas, criação de esgotamento sanitário em partes do município e implantação das dependências da Petrobrás.

\begin{tabular}{ccc|}
$\begin{array}{c}\text { Tempo de } \\
\text { residência } \\
\text { (anos) }\end{array}$ & $\begin{array}{c}\text { Madre de } \\
\text { Deus } \\
(\%)\end{array}$ & $\begin{array}{c}\text { Saubara } \\
(\%)\end{array}$ \\
\hline 252 & 0 & \\
$55-10$ & 1,6 & 2,6 \\
$10=20$ & 17,5 & 25,6 \\
$20-30$ & 74,2 & 35,9 \\
\hline
\end{tabular}

Tabela 1: Percentual dos entrevistados segundo tempo de residência em MD e SB

Quanto à escolaridade, o maior número de entrevistados e familiares tem somente o $1^{\circ} \mathrm{Grau}$ incompleto (tabela 2).

\begin{tabular}{|lcc|}
\multicolumn{1}{|c}{ Escolaridade } & MD $\left(\mathbf{N}^{\mathbf{0}}\right)$ & SB $\left(\mathbf{N}^{\mathbf{0}}\right)$ \\
\hline Alfabetização & 19 & 43 \\
$1^{\circ}$ grau incompleto & 166 & 79 \\
$1^{\circ}$ completo & 4 & 7 \\
$2^{\circ}$ grau incompleto & 17 & 11 \\
$2^{\circ}$ grau completo & 33 & 11 \\
Superior incompleto & 0 & 0 \\
Superior completo & 4 & 0 \\
\hline
\end{tabular}

Tabela 2: Grau de instrução dos entrevistados em MD e SB

As principais fontes de renda dos entrevistados são a mariscagem, a aposentadoria e auxílios dos programas sociais (Gráfico 1 ). Observa-se a diferença na importância da pesca, com $18 \%$ em Saubara e apenas 3\% em Madre de Deus. 
$\mathrm{MD}$

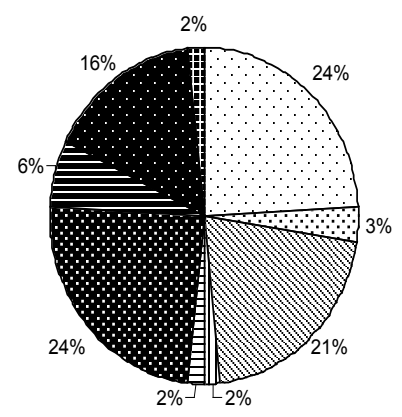

$\mathrm{SB}$

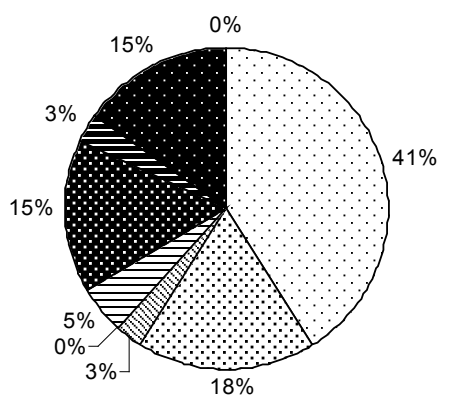

$[\because$ pesca

皿 autônomo (comércio)

aposentadoria

- programa social

Gráfico 1: principais fontes de renda dos entrevistados em MD(a) e SB (b).

Se em Madre de Deus, o emprego com carteira assinada é mencionado como fonte de renda por um quinto dos entrevistados, em Saubara este tipo de fonte de renda aplica-se só a $1 \%$ dos entrevistados. Esta realidade está relacionada ao processo histórico de ocupação do município, que teve como principais rendas a agricultura, a produção de sal, a criação de peixe, assim como a pesca e a mariscagem. Em Madre de Deus, anteriormente rota de escoamento de produtos do Recôncavo e posteriormente área de veraneio, sofreu a partir da década de 50 uma importante mudança econômica. A implantação da Petrobrás agiu como um dos principais atrativos para a intensa ocupação e implantação de indústrias, até em municípios próximos.

Nos dois municípios a população de baixa renda recebe auxílio disponibilizado pelo Governo Federal como o "Bolsa Família" e outros oferecidos pelas prefeituras dos próprios municípios.
Observa-se casos de complementaridade de fontes de renda. Em Madre de Deus, quem sobrevive da mariscagem complementa sua renda através dos programas sociais. A mariscagem como segunda opção de renda para quem tem como principal fonte de renda uma aposentadoria, um emprego com carteira assinada ou a pesca. Em Saubara, os programas sociais encontram-se também como segunda fonte de renda, embora há quem sobreviva somente da mariscagem segundo alguns entrevistados. A mariscagem é considerada uma segunda fonte de renda para quem é aposentado, pensionista, empregado com carteira assinada, trabalhador informal ou pescador.

As atividades desenvolvidas pelos entrevistados refletem no valor total de sua renda, que em geral é baixa e não passa de dois salários mínimos, com algumas exceções. Em Madre de Deus quase $50 \%$ dos entrevistados vivem com menos de um salário mínimo. Em torno de $45 \%$ 
vivem com renda entre um e dois salários mínimos e menos de $10 \%$ vivem com mais de dois salários mínimos. Em Saubara esses valores caem ainda mais. Quase $78 \%$ dos entrevistados vivem com menos de um salário mínimo e o percentual restante recebe no máximo dois salários mínimos.

Esses valores baixos explicam a pluralidade de fontes de renda, revelando a importância de direitos trabalhistas como a aposentadoria rural e de programas sociais para a estabilidade social da população. Percebe-se que essas fontes públicas são mais elevadas no município industrializado. Mostra que o avanço do meio técnico-científico-informacional não se traduz automaticamente por inclusão de todos os segmentos da população (SANTOS, 2006). Ao contrário produz exclusão, agravada na ausência de um suporte do poder público através das citadas políticas públicas, mas também agravada pela degradação ambiental provocada, o que diminui a autonomia de populações que vivem em dependência estreita da natureza, autonomia melhor preservada em Saubara. De fato nesse município, embora a renda monetária seja inferior a levantada em Madre de Deus, os habitantes ainda têm acesso a recursos naturais mais abundantes e de qualidade.

Em contrapartida foi verificado que em Madre de Deus as condições sanitárias são mais favoráveis que em Saubara. Contudo o tratamento de água para consumo não é feito por todos os entrevistados, com quase $30 \%$ em Madre de Deus e em torno de $60 \%$ em Saubara. Os tratamentos de água como filtração, fervura e cloração estão respectivamente em torno de 66, 5 e $3 \%$ em Madre de Deus, contra 38\% somente de filtração em Saubara.

As redes de esgoto nos bairros entrevistados de Madre de Deus são geralmente antigas e direcionadas para o manguezal, tendo como destino final o Canal de Suape. O antigo sistema de esgotamento sanitário das localidades estudadas em Madre de Deus foi instalado pela prefeitura no período de intenso crescimento do atual município, após a instalação da Petrobrás e outras empresas. Apenas $8 \%$ dos entrevistados possuem em sua residência fossa séptica; $89 \%$ descartam seus resíduos em vala com destino ao manguezal. No município de Saubara boa parte da população que reside próximo aos manguezais não está ligada à rede de esgotamento sanitário, fazendo desta forma uso de valas para descarte de resíduos ou uso de poucas tubulações que tendem aos manguezais. Para compensar essa deficiência, $74 \%$ dos entrevistados contam com a existência de fossas sépticas. A coleta de lixo nas localidades estudadas em Madre de Deus é realizada diariamente. Em Saubara, o lixo é também coletado, porém certos moradores o queimam ou o descartam em terreno baldio. Através dos dados obtidos é possível perceber a pouca ou quase inexistência de infraestrutura pública nas localidades estudadas, contrastando com a existência de rede de esgotamento sanitário nos respectivos centros dos municípios.

\section{Mariscagem}

Nos dois municípios analisados, a mariscagem está associada a outros tipos de fonte de renda, porém em Saubara esta atividade é predominante, com o percentual de $92 \%$ dos entrevistados que coletam para consumo e venda contra 63\% em Madre de Deus.

No município de Madre de Deus 87\% dos entrevistados vendem no próprio município. Em Saubara $77 \%$ dos entrevistados vendem os mariscos no próprio município, incluindo a venda direta em praias como Cabuçú e Bom Jesus dos Pobres.

Pode ser observado nos gráficos $2 a$ e $2 \mathrm{~b}$ o longo tempo de experiência dos entrevistados, o que se explica em parte por uma iniciação à atividade na infância na maioria dos casos. À diferença da pesca em que o pescador necessita de auxílio tanto para a locomoção das embarcações quanto ao manuseio das redes, a mariscagem é uma atividade que pode ser desenvolvida sozinha, ou seja, os marisqueiros têm acesso aos manguezais a pé e utilizam utensílios baratos que facilitam a retirada dos moluscos e crustáceos, como verificado com $47 \%$ dos entrevistados em Madre de Deus e 38\% em Saubara. 

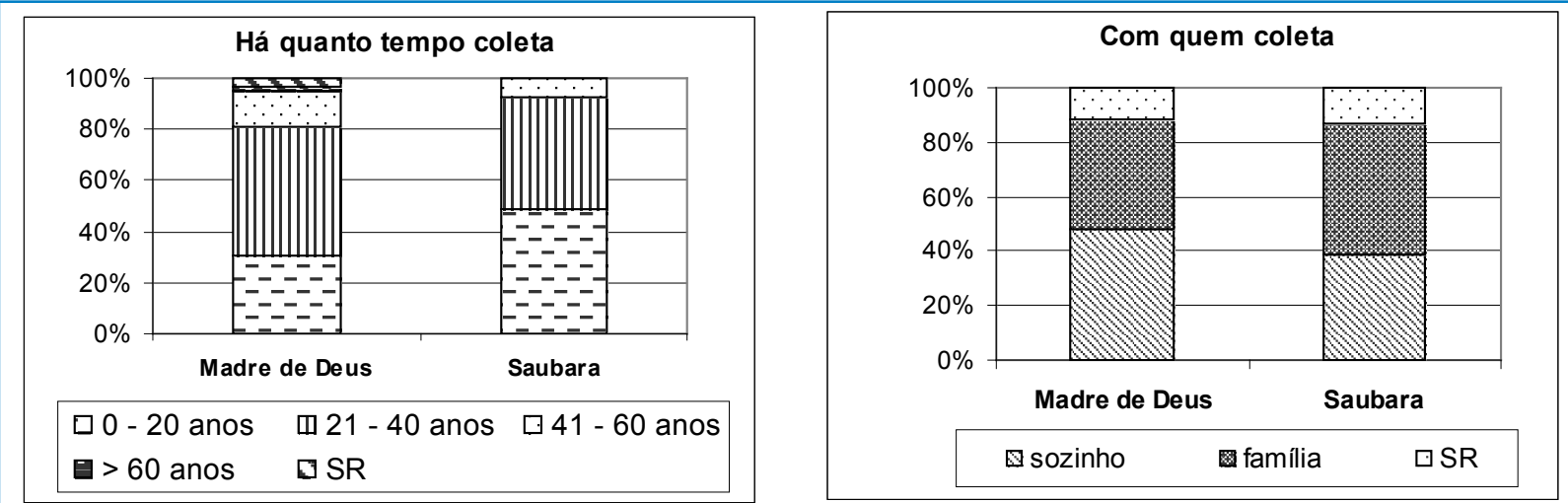

Gráfico 2: Tempo de coleta (a) e participação dos familiares (b) dos entrevistados na atividade em MD e SB.

Observa-se uma alta freqüência de coleta entre os entrevistados, apesar da variedade mencionada das fontes de renda.

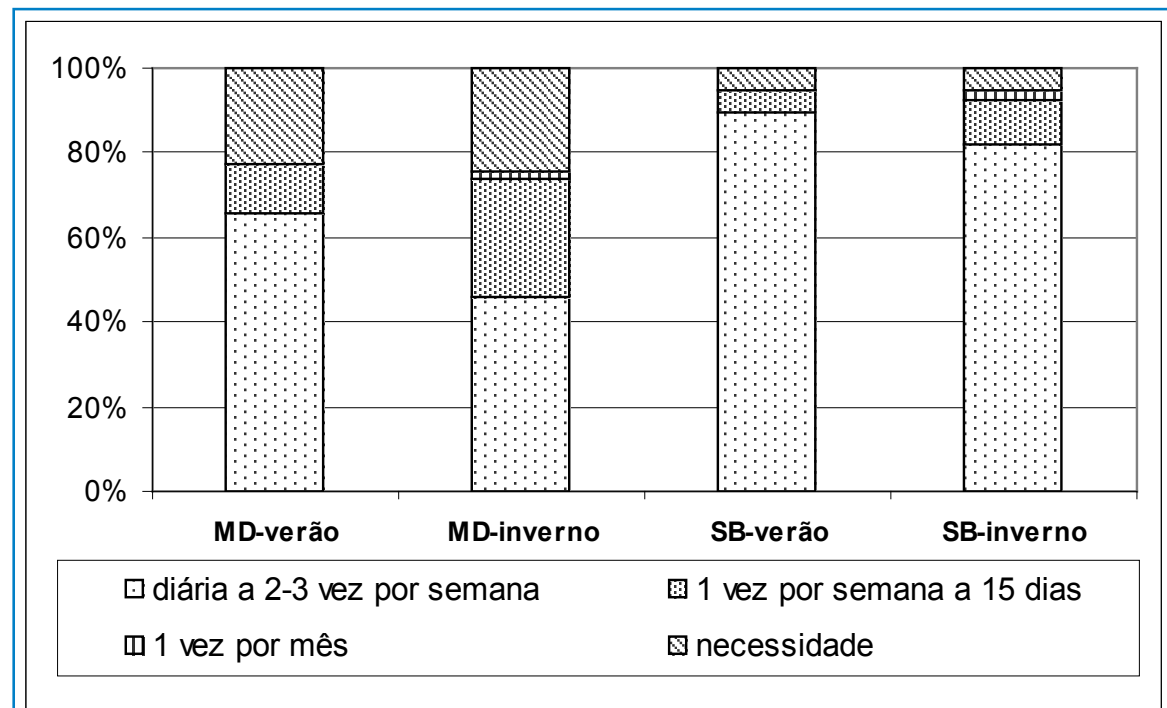

Gráfico 3: periodicidade de coleta das espécies em MD e SB.

As espécies do manguezal mais coletadas são o chumbinho ou bebe-fumo (Anomalocardia brasiliana), a ostra (Crassostrea rhizophorae), o siri (Callinectes danae) e o sururu
(Mytella falcata). Isso se deve principalmente a época de reprodução destas espécies, que em geral acontece durante todo o ano, embora apresente períodos de maior reprodução. No caso específico 
de Madre de Deus, essas capturas se explicam também possivelmente pela sua resistência aos contaminantes na região.

O chumbinho em Madre de Deus é coletado durante todo ano, não havendo períodos de maior e menor extração. No município de Saubara, o período de maior extração da espécie, para um número significativo de entrevistados, é no inverno, devido ao número de dias com temperaturas mais amenas, pois a incidência do sol sobre os marisqueiros é menor, favorecendo o aumento do número de horas no local de coleta.

Nos dois municípios foi relatada uma redução significativa dos mariscos nas últimas décadas por parte dos entrevistados. A redução, de acordo os entrevistados está associada aos frequentes derrames de óleo e aos efluentes tanto industriais quanto domésticos, e ao aumento do número de marisqueiros e marisqueiras. Em Saubara a redução dos mariscos é atribuída ao fenômeno da Maré Vermelha ocorrido em 2007 e ao aumento da temperatura em dias muito ensolarados (Gráfico 4). Houve uma redução significativa nas últimas décadas nos dois municípios e abrangeu todas as espécies. Há espécies que já não são mais encontradas.

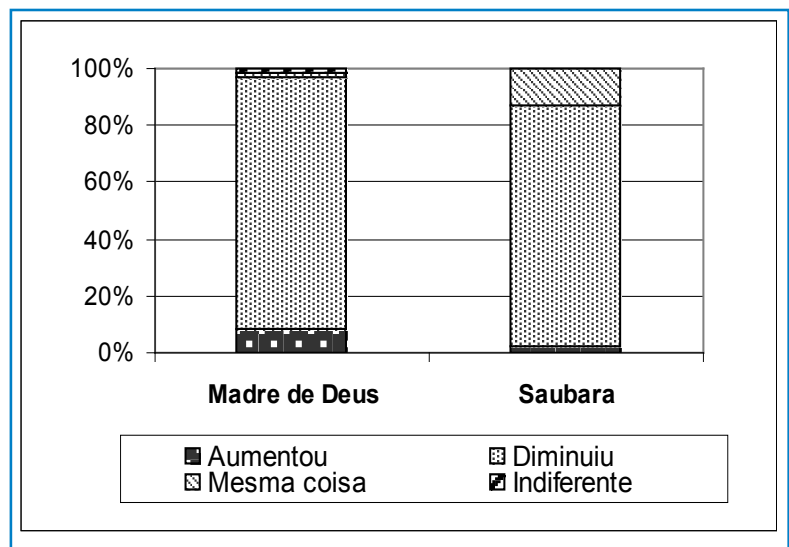

Gráfico 4: mudanças relaciondas à coleta dos mariscos em MD e SB.

Foi verificado que $58 \%$ dos entrevistados em Madre de Deus e $51 \%$ em Saubara desconhecem o período de reprodução das espécies mais coletadas, especialmente no tocante ao chumbinho. O conhecimento acerca do período de reprodução das espécies de uma determinada região é algo muito importante, pois desta forma é possível manter um controle sobre a extração da fauna e evitar uma superexploração. Ora verificase que nas áreas em que são realizadas atividades artesanais como a pesca e a mariscagem, à medida que vão se industrializando, perde-se gradativamente estes saberes tradicionais. Isso se reflete diretamente sobre os recursos naturais e sobre as populações tradicionais que dependem destes desses recursos.

O ecossistema manguezal, além de ser uma fonte de inúmeras espécies de moluscos e crustáceos, é utilizado como fonte de madeiras para serem utilizadas como lenha. Porém, um número muito pequeno de pessoas em Madre de Deus afirmou retirar vegetação seca de manguezal, tendo um número maior em Saubara. A fraqueza deste uso está associado à legislação ambiental, que proíbe o corte de árvores uma vez que áreas de manguezais integram áreas de preservação permanente (BRASIL, 1965; 2002).

A redução dos manguezais, segundo os entrevistados, deve-se aos sucessivos derrames de óleo. O primeiro ocorreu na década de 60, depois em 1992 com a liberação de 48.000 litros de óleo, um dos maiores na história da Baía de Todos os Santos, e os demais nos anos 1998, 1999, 2000, 2001, 2002, 2005 e 2009, de acordo com relatos de pescadores e estudo realizado por Veiga (2003). Aconteceram em decorrência de manobras de navios petroleiros ou rompimento de dutos.

Entre 1999 e 2001 ocorreram inúmeros acidentes ambientais, atingindo não somente o município de Madre de Deus e menos intensamente Saubara, mas todo o norte da Baía de todos os Santos. São comprovados através de estudos que indicaram a presença de hidrocarbonetos e metais pesados oriundos dos derrames e dos vestígios de óleo que podem ser identificados visualmente no ambiente. Foram constatadas também altas concentrações de 
hidrocarbonetos policíclicos aromáticos (HPA) em áreas portuárias e de transporte e em áreas de produção de petróleo (CELINO e QUEIROZ, 2006), o que confere à vegetação de manguezal, dentre outras consequências, a presença de folhagens amareladas, perfuradas ou enrugadas. Em Madre de Deus há ainda a presença de dutos instalados em várias localidades do município, configurandose, segundo Veiga (2003, p. 23), "num importante tensor ambiental", pois atravessam áreas de manguezal.

Houve muitos cortes de vegetação de mangue para a construção de casas, reflexo do fluxo migratório populacional e do uso histórico que se mantém; "os desmatamentos e as queimadas para a produção artesanal de carvão são práticas comuns entre os habitantes dos manguezais da Baía de Todos os Santos" (VEIGA, 2003, p. 24), apesar da legislação que contempla o corte de árvores de manguezal como crime. Os despejos de esgoto são reflexo da falta de política ambiental por parte dos poderes públicos pois ainda não vêem o ecossistema manguezal como produtivo e de suma importância para a costa marítima. O lançamento dos efluentes contribui de maneira significativa para o aumento do teor de matéria orgânica, assim como para a alteração físico-química do ambiente, o que pode contribuir para a disponibilidade de elementos químicos já existentes provenientes de atividades industriais ou associados aos efluentes, tanto para o meio quanto para a biota e, consequentemente para o homem. Estudos na BTS apontam a presença dos metais traço $\mathrm{Cr}, \mathrm{Zn}$, $\mathrm{Cu}, \mathrm{Ni}, \mathrm{Pb}$ e Cd (HATJE, et al., 2006; GARCIA et al., 2007; CELINO et al., 2008) que, em áreas pontuais próximas principalmente às indústrias, podem ser encontrados em elevadas concentrações.

Em compensação, o aumento do manguezal está associado, de acordo com os entrevistados, ao replantio de mangues atribuído à ONG $A$ Mangue, ao cuidado da população e à conscientização. Contribuiu para o aumento da área de manguezal na última década, porém não tão significativamente se comparada à perda observada desde o início da atividade petrolífera.
Assim puderam ser registrados depoimentos de marisqueiros e marisqueiras em que relataram: "lugares que antes era fechado e agora é aberto", "falta lama", e "a ostra não fixa mais". Há ainda o assoreamento do canal e da praia: "a praia toda tem mudado". A redução citada está relacionada ao período intenso de ocupação logo após a instalação da Petrobrás e empresas, o que acarretou uma diminuição significativa dos manguezais. Vale ressaltar que para a instalação destas indústrias, extensas áreas de manguezais também foram destruídas.

Foi observado em Saubara o aumento do manguezal nas últimas décadas, tanto em relação ao tamanho das árvores, quanto à superfície coberta. Isto provavelmente está relacionado ao avanço do manguezal sobre os apicuns (JESUS e HADLICH, 2009). A diminuição, citada por uma parte dos entrevistados, está associada ao corte para a construção de casas e de viveiros e mais recentemente ao aumento da temperatura em dias ensolarados.

A realização de trabalhos comunitários foi citada nas entrevistas. Essas atividades em Madre de Deus são realizadas por ONGs como a $A$ Mangue, pela comunidade, pelas associações de pescadores e pela Petrobrás. Contudo a empresa realiza atividades essencialmente quando há derrames de óleo na área.

De acordo as entrevistas realizadas, em Saubara o pessoal é mais cuidadoso. Às vezes são realizados mutirões com participação de escolas, Colônia de Pescadores e população. A Colônia de Pescadores também procura conscientizar seus membros em reuniões.

Nos dois municípios há presença de Colônias de Pesca e de associações de pescadores e marisqueiras (Gráfico 5a). É através dessas organizações que são reivindicadas reparações quando há derrames ou danos causados por algum tipo de substância descartada por empresas no entorno da Baía de Todos os Santos.

Entre as principais atividades realizadas nas associações e colônias de Pescadores foram citadas reuniões e cursos oferecidos (Gráfico $5 b)$. 


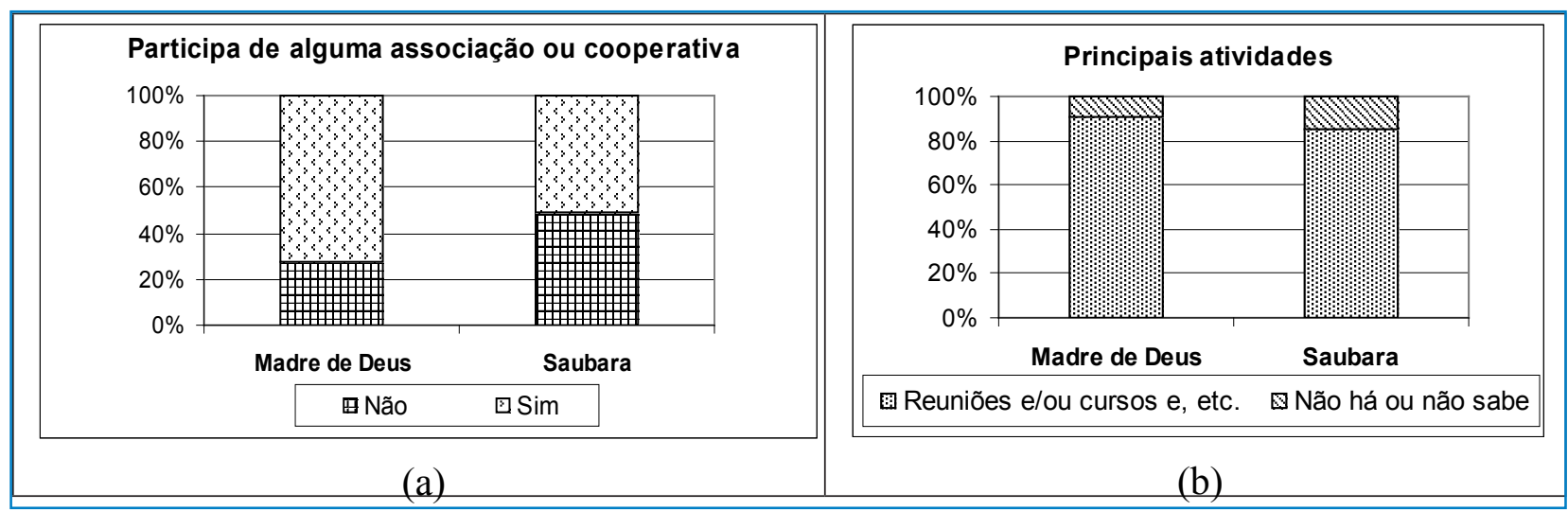

Gráfico 5: participação em associação ou cooperativa em MD e SB (a) e atividades realizadas (b).

Buscou-se levantar a percepção dos entrevistados sobre o conjunto de interações negativas entre sociedade e natureza.

Em Madre de Deus, as principais causas citadas foram os derrames de óleo, os esgotos e o lixo descartado no manguezal, o desmatamento das áreas de manguezais, os resíduos químicos e o aterramento do Canal de Suape. Observou-se uma preocupação maior no tocante aos derrames e em seguida aos esgotos. São visíveis os inúmeros dutos das redes de esgotamento sanitário do município, em que constantemente são lançados efluentes. A presença de esgoto pode estar comprometendo a qualidade dos mariscos consumidos, contribuindo para a adição de metais, coliformes fecais e outros elementos nocivos à saúde humana.

Para agravar a situação é possível encontrar manchas de oléo oriundas de derrames nos manguezais em Madre de Deus, como foi observado durante a realização do presente estudo. Esses acidentes causam impactos consideráveis sobre a fauna, a flora e o sedimento de manguezal. Após os derrames, de acordo com os entrevistados, encontra-se mariscos mortos no manguezal e na praia. A coleta fica impossibilitada e quem insiste e consome os mariscos sofre de dores estomacais dentre outros problemas. Por medida de segurança, a coleta e pesca são suspensas até que seja feita a retirada do óleo da superfície da água e das áreas afetadas pelos funcionários da Petrobrás com a participação da população. A presença de compostos derivados do petróleo pode intererir nas funcões celulares e fisiológicas e na reprodução de organismos, além de serem altamente carcinogênicos. Porém a retirada do óleo não é complemetamente realizada, pois parte acaba se infiltrando no sedimento do ecossistema manguezal e da praia e a limpeza é realizada somente na superfície.

No município de Saubara, as principais causas apontadas são os rejeitos de esgoto, o lixo, o evento da Maré Vermelha, o desmatamento, a pesca com bomba, a coleta predatória e os derrames. As duas causas que mais preocuparam foram a Maré Vermelha, que teve como principal consequência uma alta mortandade de peixes e mariscos, e o descarte de lixo nos manguezais.

No tocante à Maré Vermelha, além da alta mortandade, os pescadores foram prejudicados pela drástica redução da demanda causada pelo receio de consumir produtos do mar. Embora não cientificamente fundamentado, esse receio foi alimentado pela mídia local.

Além de todos esses problemas, nos dois municípios, foi relatada pela população e verificada em campo a extração intensa dos moluscos e crustáceos, devido em parte ao aumento da população, fato agravado pelo desconhecimento sobre o período reprodutivo.

Em Madre de Deus, $46 \%$ dos entrevistados afirmaram que os impactos foram 
reparados. As reparações mais citadas se referiram a medidas adotadas em caso de derrames, a saber: limpeza das áreas afetadas, distribuição de cestas básicas e auxílios. Alguns entrevistados citaram o replantio de mangue e limpeza por parte da prefeitura. Certos entrevistados afirmaram que há a limpeza por parte da Petrobrás, mas lamentaram não ter recebido auxílio da empresa. Em Saubara também, 50\% afirmaram a existência de reparações. Entre estas estão a distribuição de cestas básicas, o auxílio depois da Maré Vermelha durante dois meses, a limpeza das praias realizada pela prefeitura e as escolas e a retirada das torres da Petrobrás da região. Sobre este último ponto vale ressaltar que ainda podem ser encontradas torres ao nível da maré baixa, que acabam danificando as redes dos pescadores.

\section{Relação com o local}

Embora quase todos os entrevistados afirmaram gostar de seus locais de moradia, a realidade dos dois municípios corrobora para que parte dessa população busque uma qualidade de vida melhor. Cerca de um terço dos entrevistados afirma que migraria se tivesse opção para as seguintes razões: em alguns casos por questões pessoais, por causa da poluição e para conseguir um emprego. Outros $60 \%$ indicaram que não sairiam dos locais em que vivem em razão da disponibilidade dos recursos da natureza e dos laços sociais.

A partir das necessidades citadas pelos entrevistados é possível perceber as principais carências nos dois municípios, já verificadas em estudos anteriores. Falta no município de Madre de Deus emprego, serviços de saúde, cursos para a população, qualidade ambiental (conservação dos manguezais, controle dos derrames, despoluição), lazer, educação, segurança e saneamento básico. Em Saubara os entrevistados citaram emprego, infraestrutura, serviços de saúde, cooperativa de marisqueiros, comércio, educação, recursos para pescadores e marisqueiras, segurança, lazer, banco, organização e associação.

Em Madre de Deus a população está voltada para o emprego em outros setores e reinvidica sobretudo melhor infraestrutura; em
Saubara a população também quer uma melhor infraestrutura, porém dá preferência à exploração dos seus recursos naturais como fonte de renda.

\section{CONSIDERAÇÕES FINAIS}

O estudo realizado nos municípios de Madre de Deus e Saubara permitiu inferir sobre as condições socioeconômicas e ambientais das populações que têm como fontes de renda atividades tradicionais como a pesca e a mariscagem.

Porém a mariscagem sofreu interferências devido ao comprometimento dos manguezais, isso mais intensamente Madre de Deus, como reflexo do modo de ocupação do município e do modo de produção industrial que implica em altos riscos.

Primeiramente voltada para a atividade agrícola e pecuária e posteriormente para veraneio, mais recentemente o município de Madre de Deus recebeu a instalação da Petrobrás. A implantação da empresa e a intensa ocupação da ilha de Madre de Deus acarretaram inúmeras consequências negativas para o meio ambiente, entre elas a destruição das áreas de manguezais, a ocupação de encostas e apicuns e a contaminação dos manguezais por resíduos residenciais e industriais.

Saubara passou por modificações, porém muito menos intensas. O município vive do comércio, da agricultura, de serviços, mas principalmente da atividade de pesca e mariscagem. Como uma das consequências, suas áreas de manguezais são mais preservadas. Porém já são perceptíveis os primeiros impactos negativos devido às atividades industriais e petrolíferas no norte da Baía de Todos os Santos, como a redução de pescado e mariscos.

Através das entrevistas, foi possível verificar que os entrevistados em Saubara são mais dependentes das atividades artesanais como a pesca e a mariscagem que os de Madre de Deus, devido principalmente à falta do desenvolvimento de atividades no município que gerem empregos.

Ficou evidente que a atual realidade dos marisqueiros e marisqueiras assim como o atual estado de degradação dos manguezais são 
reflexos do modo de produção existente no Brasil e no mundo, assim como a perda cultural dessas atividades tradicionais.

Desta forma, percebe-se que há uma necessidade de políticas públicas voltadas para estas populações, porém não pautadas em modelos econômicos de privilégio ao capital, mas voltada para este grupo, que embora diante de

\section{Bibliografia}

BAHIA. Centro de Estatística e Informações, Companhia de Desenvolvimento da Região Metropolitana de Salvador. Informações básicas dos municípios baianos: região metropolitana de Salvador. Salvador: CEI/CONDER, 1994.

BARROS, J. S. Saubara dos cantos, contos e encantos. Salvador: Secretaria da Cultura e Turismo, 2006, $214 \mathrm{p}$.

BRADLEY, S. P. ; DANTAS, Z. M.; SALDANHA, M. G. Gestão ambiental de uma cidade-indústria: o caso de Madre de Deus. 2000. 38 f. Monografia (Especialização em Gerenciamento e Tecnologias Ambientais na Indústria) - Escola Politécnica, Universidade Federal da Bahia, Salvador. sd. Orientador (s): Profa. Lígia Nunes Costa; Prof. Asher Kiperstok. Disponível em: <http://intranet/ monografias/cidade_industria/completa.htm $>$. Acesso em: 20 maio 2009.

BRASIL. Conselho Nacional do Meio Ambiente - CONAMA. Resolução n० 303. Dispõe sobre os parâmetros, definições e limites de Áreas de Preservação Permanente. Publicado no D. O. U. em 20 de março de 2002.

BRASIL. Lei $\mathbf{n}^{\circ} \mathbf{4 . 7 7 1}$. Institui o novo código florestal. Publicado no D. O. U. em 15 de setembro de 1965.

BRASIL. Ministério das Minas e Energia. Projeto RADAMBRASIL - folha SD. 24 Salvador: geologia, geomorfologia, pedologia, vegetação e uso potencial da terra. Rio de Janeiro: MME/ RadamBrasil, 1981.

BRITO, R. R. C. de. Ambientes aquáticos. In: QUEIROZ, A. F. de S (org.). Baía de Todos os Santos: diagnóstico sócio-ambiental e subsídios para gestão. Salvador: GERMEN/UFBA-NIMA, 1997, p. 71-78.
CARDOSO, E. S. Da apropriação da natureza à construção de territórios pesqueiros. GEOUSP - Espaço e Tempo, São Paulo, n. 14, 2003, p. 119-125.

CELINO, J. J.; QUEIROZ, A. F. de S. Fonte e grau de contaminação por hidrocarbonetos policíclicos aromáticos (HPAs) de baixa massa molecular em sedimentos da Baía de Todos os Santos, Bahia. Revista Escola de Minas, Ouro Preto, n. 3, v. 59, jul./set. 2006, p. 265-270.

CELINO, J. J.; OLIVEIRA, Olívia M. C. de.; HADLICH G. M.; QUEIROZ A. F. de S.; GARCIA, K. S. Assessment of contamination by trace metals and petroleum hydrocarbons in sediments from the tropical estuary of Todos os Santos Bay, Brazil. Revista Brasileira de Geociências, n. 4, v. 38, dez. 2008, p. 753-760.

COUTO, V. de A.; AZIZ, C.; ROCHA, A. G. P. Caracterização sócio-econômica. In: QUEIROZ, A. F. de S (org.). Baía de Todos os Santos: diagnóstico sócio-ambiental e subsídios para gestão. Salvador: GERMEN/UFBANIMA, 1997, p. 167-182.

DOMINGUEZ, J. M. L.; BITTENCOURT, A. C. S. P. Geologia. In: HATGE, V.; ANDRADE, J. B. Baía de Todos os Santos: aspectos oceanográficos. Salvador: EDUFBA, 2009, p. 25-66.

FONSECA, C. Evolução da ocupação do território: asiáticos e europeus na disputa pela Baía. In: QUEIROZ, A. F. de S (org.). Baía de Todos os Santos: diagnóstico sócio-ambiental e subsídios para gestão. Salvador: GERMEN/UFBA-NIMA, 1997, p. 31-42.

GARCIA, K. S.; OLIVEIRA, O. M. C. de; QUEIROZ, A. F. de; ARGÔLO, J. L. Geoquímica de sedimentos 
de manguezais em São Francisco do Conde e Madre de Deus, BA. Geochimica Brasiliensis, n. 2, v. 21,2007 , p. 167-179.

HADLICH, G. M.; UCHA, J. M. Apicuns e manguezais - Baía de Todos os Santos - 2007. 1 mapa colorido. Escala 1:100.000. Salvador: UFBA/IGEO/NEA, 2008.

HATJE, V., BARROS, F., FIGUEIREDO, D.G., SANTOS, V.L.C.S., PESO-AGUIAR, M.C.,. Trace metal contamination and benthic assemblages in Subaé estuarine system,

Brazil. Marine Pollution Bulletin, v. 52, 2006, p. 969-987.

IBGE. Instituto Brasileiro de Geografia e Estatística. Censo 2010, primeiros resultados. Rio de Janeiro, IBGE, 2010. Disponível em: <http://www. ibge.gov.br/cidadesat/topwindow.htm?1> Acesso em: 23 dez. 2010.

JESUS, R. S. de; HADLICH, G. M. Análise multitemporal de apicuns em Madre de Deus e Saubara, Bahia. In: Simpósio Brasileiro de Sensoriamento Remoto, XIV, 2009, Natal. Anais... Natal: INPE, 2009, p. 5881-5886.

OLIVEIRA, W. F. Evolução sócio-econômica do recôncavo baiano. In: QUEIROZ, A. F. de S. (org.). Baía de Todos os Santos: diagnóstico sócioambiental e subsídios para gestão. Salvador: GERMEN/UFBA-NIMA, 1997, p. 43-56.
ONG TERCEIRA VIA. Madre de Deus e seu processo histórico/geográfico. 2005.

Disponível em: < http://www.madrededeus.com/ nhistoria.cfm?Noticia_ID $=185>$. Acesso em: 15 out. 2008.

PIMENTEL, M. S. A influência da instalação do terminal Almirante Alves Câmara nos índices socioeconômicos do município de Madre de Deus. Cadernos de Pesquisa NPGA, Salvador, n. 1, v. 3, 2006, p. 1-22.

SANTOS, M. A natureza do espaço: técnica e tempo, razão e emoção. 4. ed. São Paulo: Editora da Universidade de São Paulo, 2006, 388 p.

SOUTO, F. J. B. O bosque de mangues e a pesca artesanal no Distrito de Acupe (Santo Amaro, Bahia): uma abordagem etnoecológica. Acta Scientiarum Biological Sciences, Maringá, v. 30,2008 , p. 275-282.

VANNUCCI, M. Os manguezais e nós: uma síntese de percepções. Tradução de Denise NavasPereira. 2. ed. São Paulo: EDUSP, 2002, 304 p.

VEIGA, I. G. Avaliação da origem de hidrocarbonetos em sedimentos superficiais de manguezais da região norte da Baía de Todos os Santos, Bahia. 2003. 205 f. Dissertação (Mestrado em Engenharia de Reservatório e de Exploração) - Centro de Ciência e Tecnologia, Universidade Estadual do Norte Fluminense. Macaé. 